\title{
Synthesis and Characterization of Silver Nanoparticles from Ashyranthus aspera Extract for Antimicrobial Activity Studies
}

\author{
SWETHA, V; LAVANYA, S; SABEENA, G; PUSHPALAKSMI, E; JENSON \\ SAMRAJ, J; *ANNADURAI, G
}

\author{
Division of Nanoscience, Sri Paramakalyani Centre of Excellence in Environmental Sciences, Manonmaniam Sundaranar University, \\ Alwarkurichi - 627412, India \\ *Corresponding Author Email: gannadurai@msuniv.ac.in
}

\begin{abstract}
Development of biologically inspired experimental processes for the synthesis of nanoparticles is evolving into an important branch of nanotechnology. Plant-mediated synthesis of nanomaterials has been increasingly gaining popularity due to its eco-friendly nature and cost-effectiveness. In the present study, we were synthesized silver (Ag) nanoparticles using aqueous extracts of fresh leaves of Ashyranthus aspera medicinal plants as bio-reducing agents. UV-Vis spectrometer used to monitor the reduction of Ag ions and the formation of AgNPs in the medium. UV-Vis spectra and visual observation showed that the color of the fresh leaf extracts of Ashyranthus aspera turned into grayish-brown respectively, after treatment with Ag precursors. XRD and SEM have been used to investigate the morphology of prepared AgNPs. The peaks in the XRD pattern are associated with that of the Face-Centered-Cubic (FCC) form of metallic silver. TGA/DTA results associated with weight loss and exothermic reaction due to the desorption of chemisorbed water. FTIR was performed to identify the functional groups which form a layer covering AgNPs and stabilize the AgNPs in the medium. Moreover, silver nanoparticles using aqueous leaf extracts of Ashyranthus aspera were separately tested for their antibacterial activity against Gram-positive bacteria (Staphylococcus aureus) and Gram-negative bacteria (Enterobacter). The results showed that the bacterial growth was inhibited by the extracts containing AgNPs Nanoparticles. The biosynthesized nanoparticle was prepared from Ashyranthus aspera leaf extracts exhibits potential applications as broad-spectrum antimicrobial agents.
\end{abstract}

\section{DOI: $\underline{\text { https://dx.doi.org/10.4314/jasem.v24i7.6 }}$}

Copyright: Copyright $(\mathrm{C} 2020$ Olawepo et al. This is an open access article distributed under the Creative Commons Attribution License (CCL), which permits unrestricted use, distribution, and reproduction in any medium, provided the original work is properly cited.

Dates: Received: 16 May 2020; Revised: 29 June 2020; Accepted: 07 July 2020

Keywords: Ashyranthus aspera, Silver Nanoparticles, Plant extracts, Bacteria, Antibacterial activity.

Nanoparticles represent a particle with a nanometer size of $1-100 \mathrm{~nm}$. The nanoscale material has new, unique, and superior physical and chemical properties compared to its bulk structure, due to an increase in the ratio of the surface area per volume of the material/particle (Cushing, et al., 2004). The most widely studied nanoparticle materials are metal nanoparticles especially copper and silver because they are easier to synthesize and have diverse applications (Sasidharan et al., 2020). Moreover, these materials have a wide range of applications: detectors, catalysts, surface coating agents, and antibacterial/antimicrobials, among many others. Despite the existence of numerous metals in nature, only a few of them such as gold, silver, palladium, and platinum are synthesized extensively in the nanostructured form (Yang et al., 2017; Sathishkumar et al., 2009; Gan et al., 2018). Among the abovementioned metals, silver nanoparticles have attracted much attention due to their unique characteristics for utilizing in the various application (Arvizo et al., 2012; Bhattacharya et al., 2008; Awwad, et al., 2013).
Conventional physical and chemical methods presently have limited use in preparing metal nanoparticles due to toxic chemicals (Singhal et al., 2013). Moreover, these methods are associated with high-energy input and costly downstream processing (Anupam Roy et al., 2019). Green synthesis of nanoparticles makes use of environmentally friendly, non-toxic, and safe reagents. Nanoparticles synthesized using biological techniques or green technology have diverse natures, with greater stability and appropriate dimensions since they are synthesized using a one-step procedure. Plants provide a better platform for nanoparticles synthesis as they are free from toxic chemicals as well as contain natural capping agents (Henry et al., 2018). The synthesis of metal nanoparticles elicited high interest among the researchers and nanotechnologists. Efforts are made to prepare green synthesized nanoscale objects with different metals like copper, zinc, titanium, magnesium, gold, and silver. Other green synthesized metals like gold with their low-dimensional structure (Solomon et al., 2007). Ag nanoparticle is an 
interesting metal to be studied, especially in the field of health and medicine. Ag is a strong antibacterial and also toxic to cells. Ag can damage bacterial cell walls, inhibits bacterial cell growth, and disrupts cell metabolism because of the interaction between $\mathrm{Ag}$ ions with macromolecules in cells, such as proteins and deoxyribonucleic acid (DNA). The ion Ag that interacts with the cell prevents protein synthesis, further decreases the membrane permeability, and eventually leads to cell death. The Ag nanoparticles are chemically more reactive than $\mathrm{Ag}$ in their bulk. Therefore, Ag nanoparticles are indicated to have stronger antibacterial capabilities (Jirovetz, et al., 2003). Green synthesis methods for synthesizing nanoparticles using natural products can be used to address the problem by utilizing plants or microorganisms (Chandran et al., 2006). The utilization of plants in the biosynthesis of nanoparticles involves the content of secondary metabolites as reducing agents (Ashok et al., 2018). Allegedly, biological agents act as reducers, stabilizers, or both in the process of forming nanoparticles (Das et al., 2013). In this context, plantmediated NPs synthesis seems to be cost-effective as well as eco-friendly method. Moreover, NP synthesis from plants with medicinal properties proves to be beneficial in treating various ailments in a better and easy way. On such a plant is Achyranthes aspers, which is distributed as a weed throughout India, tropical Asia, and other parts of the world. Ayurvedic, Yunani practitioners, and Kabirajes use different parts of this plant to treat leprosy, asthma, fistula, piles, arthritis, wound, insect and snake bite, renal and cardiac dropsy, kidney stone, diabetes, dermatological disorders, gynecological disorders, gonorrhea, malaria, pneumonia, fever, cough, pyorrhea, dysentery, rabies, hysteria, toothache, etc. The plant is a popular folk remedy in traditional system of medicine throughout the tropical Asian and African countries. The plant is reported to be used as an antimicrobial, larvicidal, antifertility, immunostimulant, hypoglycemic, hypolipidemic, anti-inflammatory, antioxidant, diuretic, cardiac stimulant, antihypertensive, antianasacra, analgesic, antipyretic, antinoiceptive, prothyrodic, antispasmodic and hepatoprotective (Qais et al., 2018). The present study synthesized Ag nanoparticles using aqueous extracts of fresh leaves of Ashyranthus aspera and then evaluated its antibacterial activity, particularly against the growth of Gram-positive bacteria (Staphylococcus aureus) and Gram-negative bacteria (Enterobacter).

\section{MATERIALS AND METHODS}

Chemicals and Plant Material Collection: All the reagents purchased were of analytical grade and used without any further purification. Silver nitrate $\left(\mathrm{AgNO}_{3}\right)$ was purchased from Sigma-Aldrich with $\geq$ 99.5\% purity. Fresh leaves of Ashyranthus aspera was collected from the local area land, North Sulawesi, Indonesia. Distilled water was used for preparing aqueous solutions all over the experiments.

Preparation of Leaf Extract: Aqueous leave extracts were prepared by the following procedure: fresh leaves of Ashyranthus aspera were collected and washed with tap water at first, and then the surface was washed under running water with distilled water until no impurities remained. Then, the fresh leaves were dried in room temperature in open air, shadow five days. Then $50 \mathrm{~g}$ of coarse powder was crushed dried plant material by using grinder and $10 \mathrm{~g}$ was weighed and put into a beaker with $100 \mathrm{ml}$ of distilled water. The mixture was heated for 20 minutes at $60^{\circ} \mathrm{C}$ while stirring occasionally and then allowed to cool at room temperature (Marslin et al., 2018). The mixture was filtered using the Whatman no:1 filter paper. The extract was stored in the refrigerator for further use to synthesize $\mathrm{Ag}$ nanoparticles from the $\mathrm{AgNO}_{3}$ precursor solution.

Synthesis of Ag Nanoparticles: $\mathrm{AgNO}_{3}$ powder was dissolved in distilled water to prepare a $10 \mathrm{mM} \mathrm{AgNO}_{3}$ stock solution from which a series of $1 \mathrm{mM}, 2 \mathrm{mM}, 3$ $\mathrm{mM}, 4 \mathrm{mM}$, and $5 \mathrm{mM} \mathrm{AgNO}_{3}$ solutions were prepared. The $\mathrm{AgNO}_{3}$ solutions were mixed with the aqueous extract of Ashyranthus aspera fresh leaves at a ratio of $1: 1(\mathrm{v} / \mathrm{v})$ to a volume of $50 \mathrm{~mL}$ in a flask. The flask was wrapped with an aluminum foil and was then heated in a water bath at $60^{\circ} \mathrm{C}$ for 5 hours. After different time intervals, the color change of reaction mixture is observed from transparent yellow to dark brown indicates that the formation of AgNPs and then finally silver nanoparticles were prepared. Further analyzed by using UV - Vis spectrophotometer. Furthermore, the mixture was stored in the refrigerator for the antibacterial activity test.

Antibacterial activity of biosynthesized Ag NPs: The antibacterial activity of the biosynthesized silver nanoparticles against Gram-positive and negative bacteria species was done by agar well diffusion method. Experimented bacteria were Gram-positive bacteria (Staphylococcus aureus,) and Gram-negative bacteria (Enterobacter). Preliminary antibacterial activity of silver nanoparticles was evaluated using the agar well diffusion assay as described earlier ( $\mathrm{Li}$ et al., 2004). The bacterial test organisms were grown in the nutrient broth overnight to attain the colony-forming unit (CFU) of $\sim 10^{6} \mathrm{per} \cdot \mathrm{ml}$. One hundred microlitres of each bacteria culture were spread on the Muller Hinten agar plates. Agar wells $(8 \mathrm{~mm})$ were punched 
with the help of sterilized micropipette tips and loaded with AgNPs. The plates were then incubated for $24 \mathrm{~h}$ at $37^{\circ} \mathrm{C}$, and diameters of zone of inhibition were recorded in millimeter $(\mathrm{mm})$.

\section{RESULT AND DISCUSSION}

$U V$-Visible Analysis of AgNP Synthesis: The aqueous extract of fresh leaves of Ashyranthus aspera change their colors when warmed. The Ashyranthus aspera extract changes color from yellowish-brown to brownish yellow, as shown in Fig 1. This warm extract solution changed color again after adding the $\mathrm{AgNO}_{3}$ solution. Color changes are possible because some of the $\mathrm{Ag}$ ions begin to be reduced due to the effects of heat and produce the $\mathrm{Ag}^{+}$complex.

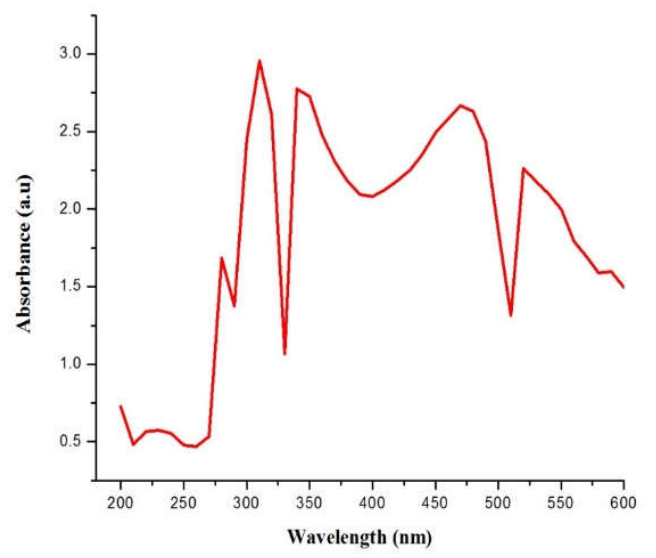

Fig 1: XRD spectrum of silver nanoparticles

This complex was responsible for changing color from brownish-yellow to grayish brown (Ashyranthus aspera). This color change indicates the formation of Ag nanoparticles (Balaji et al., 2009). The brownish color appears due to the coherent oscillation of conduction band electrons at the nanoparticle's surface, resulting in surface plasmon resonance (SPR) (Mandal et al., 2005). UV-visible spectra of the silver nanoparticle's colloidal solution synthesized using Ashyranthus aspera as a function of time caused by the reduction of $\mathrm{AgNO}_{3}$ are shown in Fig 1. There was no remarkable absorption peak just after the addition of the extract to silver nitrate solution, while a peak at $300-450 \mathrm{~nm}$ started to emerge as the color of the solution changed. The SPR band at $450 \mathrm{~nm}$ indicates the synthesis of silver nanoparticles by the Ashyranthus aspera extract that saturated after 4 hours.

Fourier transform infrared spectroscopy (FTIR): Fig 2 shows the sharp FT-IR spectrum of synthesized AgNPs located at about $3784.64 \mathrm{~cm}^{-1}, 3094.34 \mathrm{~cm}^{-1}$, $1591.65 \mathrm{~cm}^{-1}, 1401.33 \mathrm{~cm}^{-1}, 1000 \mathrm{~cm}^{-1}, 703.09 \mathrm{~cm}^{-1}$ and $3200-3000 \mathrm{~cm}^{-1}$. In the IR spectra there is no strong absorption around $3400 \mathrm{~cm}^{-1}$ to $1700 \mathrm{~cm}-1$ to show the absence of hydroxyl group. A band at $3784.64 \mathrm{~cm}^{-1}$ may indicate $\mathrm{N}-\mathrm{H}$ stretching (no band) may be 3 amines. $3094.34 \mathrm{~cm}^{-1} \rightarrow \mathrm{C}-\mathrm{H}$ stretching (aromatic) $1591.65 \mathrm{~cm}^{-1} \rightarrow$ a medium peak indicating $\mathrm{C}=\mathrm{H}$ stretching. $1401.33 \mathrm{~cm}^{-1} \rightarrow \mathrm{C}-\mathrm{H}$ deformation (in methylene group).

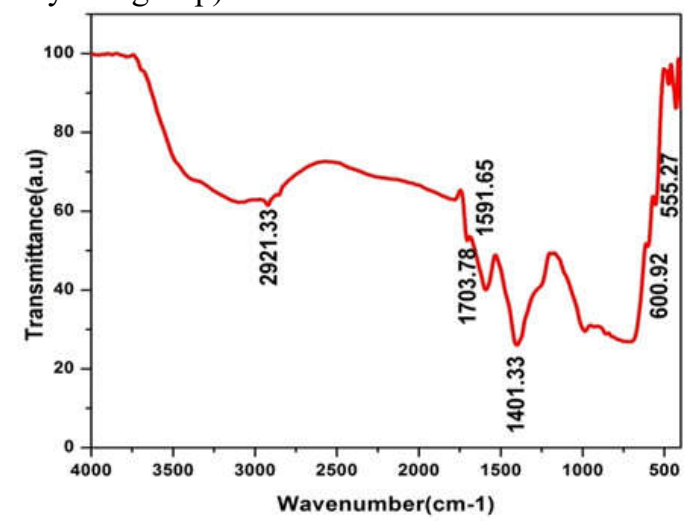

Fig 2: FTIR spectrum of silver nanoparticles

The region below $1000 \mathrm{~cm}^{-1}$ indicates the $\mathrm{C}-\mathrm{O}$ deformation and then $703.09 \mathrm{~cm}^{-1} \rightarrow \mathrm{CH}_{2}$ (rocking) $3200-3000 \mathrm{~cm}^{-1} \rightarrow$ the absorption due to $\mathrm{C}-\mathrm{H}$ stretching and AR-H stretching occurs in their region. The sharp bands of weal to medium intensities are observed. IR spectroscopic study confirmed that hydroxyl group and amines have the stronger ability to bind metal, could form a layer covering the metal nanoparticles (i.e., capping of silver nanoparticles) to prevent agglomeration and thereby stabilize the medium (Shanmuganathan et al., 2018; Oves et al., 2018). These results suggest that the biological molecules perform dual functions of the formation and stabilization of silver nanoparticles in the aqueous medium.

$X$-ray diffraction pattern (XRD): The XRD pattern of synthesized AgNPs using Ashyranthus aspera leaf extract was shown in Fig 3. The XRD was done to determine the crystalline nature of AgNPs and the resulted peaks were found at $(2 \theta) 38.12,44.30,64.44$, 64.63, 77.40 representing (111), (200), (220) and (311) face-centered cubic structure of silver which were compared with the standard powder diffraction card of Joint Committee on Powder Diffraction Standards (JCPDS), silver file No. 04-0783. Other peaks at $2 \theta$ values in Ag NPs pattern can be ascribed to the residues of the organic content of the plant extract. These peaks reveal the crystallization of some plant metabolite moieties on the surface of the Ag NPs, which is in agreement (Welch and Compton, 2006). This is a piece of acceptable evidence to confirm the involvement of the plant extract compositions in the AgNP formation. This result is following XRD analysis. 


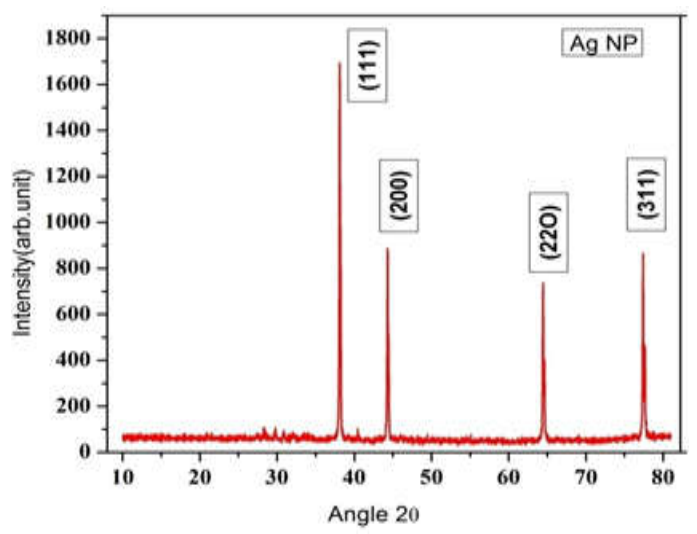

Fig 3: XRD spectrum of silver nanoparticles

Cyclic Voltammetry: Among different silver, the electrochemical properties of biosynthesized silver nanostructures were examined using cyclic voltammetry $(\mathrm{CV})$. Nanoparticles were characterized by cyclic voltammetry (CV) by direct detection of nanoparticles. Moreover, the silver nanoparticle was analyzed by $\mathrm{CV}$ to observe the possible presence of electroactive compounds that could interfere with the analysis of nanoparticles.

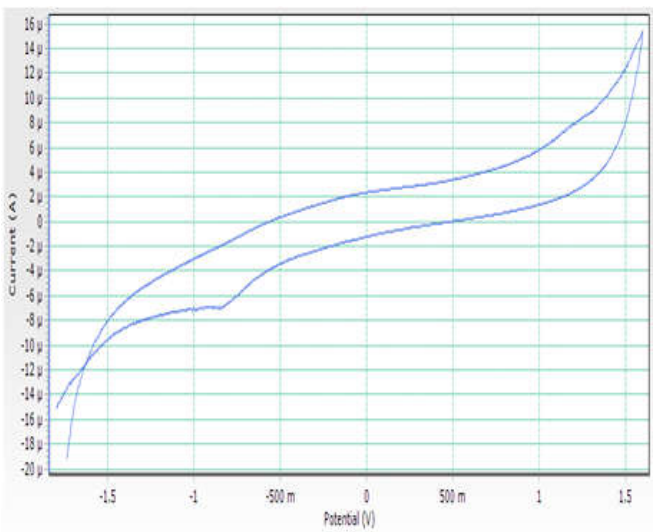

Fig 4: Cyclic Voltammetry of silver nanoparticles

\begin{tabular}{ll}
\multicolumn{2}{c}{ Table 1: Peak Analysis } \\
\hline X1: & $-1.029 \mathrm{~V}$ \\
Y1: & $-3.473 \mu \mathrm{A}$ \\
X2: & $-510.359 \mathrm{mV}$ \\
Y2: & $-3.473 \mu \mathrm{A}$ \\
Peak I: & $-3.689 \mu \mathrm{A}$ \\
Peak E: & $-979.313 \mathrm{mV}$ \\
Area: & $40.409 \mu \mathrm{C}$ \\
Range: & $-1 \mathrm{~V}$ to $-510.3 \mathrm{mV}$ \\
\hline
\end{tabular}

Results showed that the leaf extract mediated synthesis AgNPs exhibit similar redox properties as solutionsynthesized silver nanoparticles by modifying the Brust meth in the literature (Giovanni and Pumera, 2002; Hoda Erjaee and Saeed 2017). Fig .4 shows the Ashyranthus aspera extract mediated synthesis AgNPs showed the characteristic $\mathrm{CV}$ profile of traditional AgNPs. There is an apparent feature of electrochemical dissolution (stripping) of silver nanostructures on the electrode surface, at $200 \mathrm{mV}$, and reduction of the generated silver ions in the oxidative part of the cycle from the solution at +100 $\mathrm{mV}$. As it can be seen from the voltammograms, the behavior of Ashyranthus aspera extract mediated synthesis nanoparticles significantly differs, depending on the concentration of the nanoparticles, with a broadening of the peak at high concentrations, indicating a probable aggregation established that the electrochemical behavior of various silver nanoparticles significantly differs, depending on the size of the nanoparticles. Ashyranthus aspera extract mediated synthesis silver nanoparticles showed a voltammetric profile, for potential peak values and the shape of both peaks, similar to the traditional AgNPs with size higher than $40 \mathrm{~nm}$ as shown in Table 1. It can be seen that the oxidation processes of an electrode start at a much higher potential and does not influence silver detection. The presented results demonstrate the applicability of an electrode as a sensor for the detection of equivalence points in the redox reaction between silver (Milardovic et al., 2018).

Particle Size Analyzer: To analyze the particle size distribution in different trials Particle size analyzer was used (Microtrac, USA). The particle size of the synthesized AgNps was analyzed using a dynamic light scattering (DLS) particle size analyzer. The DLS particle size analysis was carried out using a standard analysis time, and the size of AgNps was found to vary between 2.8 to $92.1 \mathrm{~nm}$ as shown in Table 2. The size, topography, and shape of AgNps were measured using a DLS particle size analyzer. (Kiruba et al., 2012). Particle size measurement was done for all trials to choose the primary optimum size of nanoparticles. Based on the results, the mean size of AgNPs at optimum condition was recorded $43.1 \mathrm{~nm}$ and the range of nanoparticles was from 2.8 to $92.1 \mathrm{~nm}$ as shown in Fig 5. As expected, the Particle size analyzer measured size is slightly larger than the XRD size. As it has been mentioned previously, Particle sizes were similar to XRD measurements, while the particle sizes were significantly larger than X-ray Diffraction. The differences possibly reflect the fact that XRD only measures a number based size distribution of the physical size and does not include any capping agent, while Particle size analyzer measures the hydrodynamic diameter, which is the diameter of the particle, plus ions or molecules that are attached to the surface and moves with the AgNPs in solution. These 
ions or other associated molecules make the particle appear larger to the instrument in comparison to XRD. Hence, the hydrodynamic diameter is always greater than the size estimated by XRD. Nevertheless, many studies proposed the importance of hydrodynamic diameter for understanding and optimizing the size of nanoparticles and their performance in biological assays (Anandalakshmi et al., 2006).

Fig 5: Particle size analysis of silver nanoparticles

\begin{tabular}{lll}
\multicolumn{3}{c}{ Table 2: a) Distribution Results } \\
\hline Peak & $\begin{array}{l}\text { Diameter } \\
\text { (nm) }\end{array}$ & Std. Dev \\
\hline 1 & 2.8 & 0.9 \\
2 & 92.1 & 75.7 \\
3 & 0 & 0 \\
4 & 0 & 0 \\
5 & 0 & 0 \\
Average & 85.1 & 76.5 \\
Residual & $3.244 \mathrm{e}-003$ & $(\mathrm{O} . \mathrm{K})$ \\
\hline \multicolumn{4}{c}{} \\
biameter (d) & b) Cumulants Results \\
Polydispersity Index (P.I.) & 0.430 \\
Diffusion Const. & (D) & $1.141 \mathrm{e}-007\left(\mathrm{~cm}^{2} / \mathrm{sec}\right)$ \\
\hline
\end{tabular}

Fluorescence Spectroscopy: The FL of the synthesized bio-inspired AgNPs by Ashyranthus aspera leaf extract is also studied via fluorescence emission spectroscopy. Fluorescence (FL) spectrum is one of the methods to estimate the optical property of silver nanoparticles as photonic materials. The colloidal silver nanoparticles are dispersed in water and the FL emission spectra are recorded for the excitation wavelength at $647 \mathrm{~nm}$.

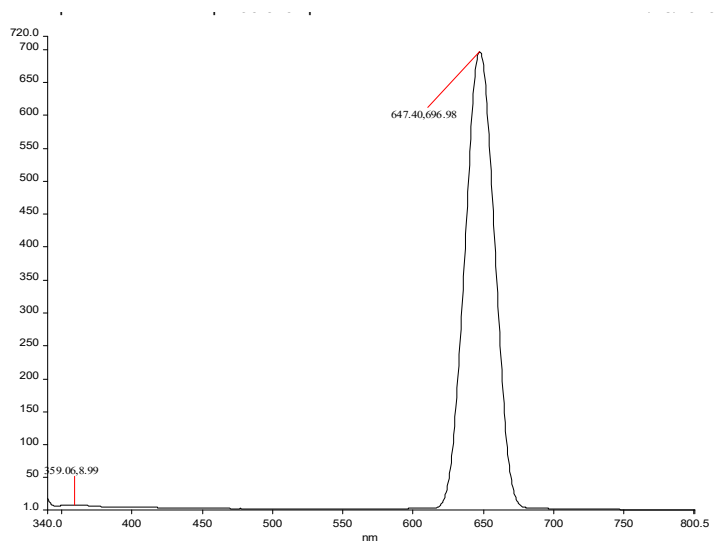

Fig 6: Fluorescence spectroscopy of silver nanoparticles

A broad emission is obtained at $698 \mathrm{~nm}$. The intensity of the fluorescence emission peak is gradually increased up to $359 \mathrm{~nm}$, after which it is slowly decreased up to $700 \mathrm{~nm}$. The present peak is redshifted (Ratan, et al., 2004). Linoleic acid during the formation of silver nanoparticles further enhances the intensity of emission. Fluorescence spectra for silver nanoparticles are shown in Fig 6. These spectra infer the possibility of the silver nanoparticle to be used as a 'nanolaser' with optical pumping (Skandalis et al., 2017).

Antibacterial activity: Table 2 shows that the antibacterial activity against Staphylococcus aureus, Enterobacter was increased. Fig 7. shown in Staphylococcus aureus was indicated by an increase in the inhibit concentration of silver nanoparticle using $25 \mu \mathrm{l}, 50 \mu \mathrm{l}, 75 \mu \mathrm{l}, 100 \mu \mathrm{l}$ and then the zone diameter from this concentration $11 \mathrm{~mm}, 11.2 \mathrm{~mm}, 11.4$ $\mathrm{mm}, 11.8 \mathrm{~mm}$ with the increasing Ag concentration in Ashyranthus aspera extract as shown in Table 3.

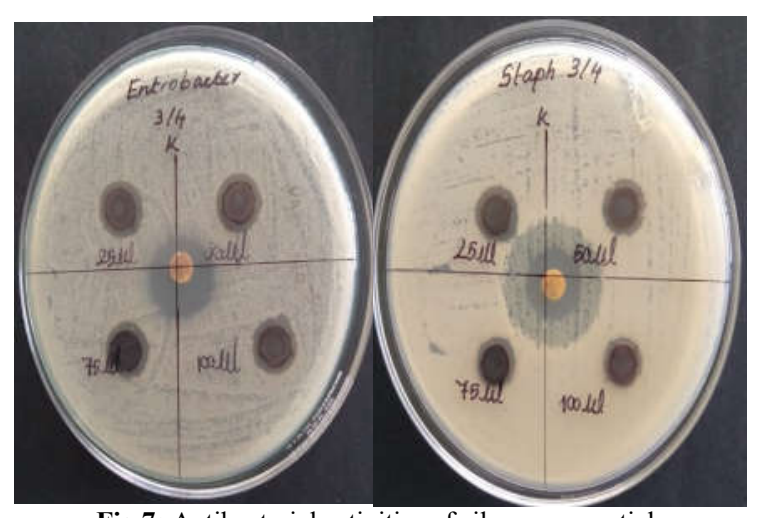

Fig 7: Antibacterial activities of silver nanoparticle

However, the opposite result was shown by Enterobacter, which was indicated by an increase in the inhibit concentration of silver nanoparticle using $25 \mu \mathrm{l}, 50 \mu \mathrm{l}, 75 \mu \mathrm{l}, 100 \mu \mathrm{l}$ and then the zone diameter from this concentration $11 \mathrm{~mm}, 12 \mathrm{~mm}, 12 \mathrm{~mm}, 13 \mathrm{~mm}$ with the increasing Ag concentration in Ashyranthus aspera extract. Ciprofloxacin positive control showed similar inhibition zone diameter, which averages above $16 \mathrm{~mm}$, for the two bacteria with the increasing Ag concentration in leaves extracts of the plants. This information was supported by data that the average size of Ag nanoparticles synthesized using Ashyranthus aspera extract was relatively smaller than that using the extract of Ashyranthus aspera. The results of this study were also supported by previous studies that the small size of Ag nanoparticles makes these particles easier to penetrate the outer wall of bacteria, enter the body, destroy the respiratory chain, and thus inhibit cell respiration, causing bacterial death (Franci and Falanga Galdiero, 2015). Regarding the inhibition zone, the antibacterial activity of $\mathrm{Ag}$ nanoparticles synthesized in this study was categorized into strong inhibitory activity (inhibition zone of 10-19 mm) according to Davis and Stout (Skandalis et al., 2017). 
Table 3: Antibacterial activity of silver nanoparticles

\begin{tabular}{llllll}
\hline Bacteria & $\mathbf{2 5 u l}$ & $\mathbf{5 0 u l}$ & $\mathbf{7 5 u l}$ & $\mathbf{1 0 0 u l}$ & Control \\
\hline Staphylococcus & 11 & 11.2 & 11.6 & 11.8 & 15 \\
Enterobacter & 11 & 12 & 12 & 13 & 17 \\
\hline
\end{tabular}

Conclusion: AgNPs began to form within 10min and higher formation yield at $70 \mathrm{~min}$ after the addition of leaf extract to silver nitrate as shown by the UV-vis spectrum at $450 \mathrm{~nm}$. It was found that the formation of AgNPs was increased with time. The XRD peaks ascribed with the FCC structure of silver. The FT-IR spectrum ascribed the biological molecules which perform dual functions of formation and stabilization of silver nanoparticles in the aqueous medium. The biosynthesized AgNPs were found to have a pronounced antibacterial activity against Staphylococcus aureus, Enterobacter.

Acknowledgement: I am V. Swetha (Register No: 17221232272008) acknowledge the research centre Sri Paramakalyani Centre for Excellence in Environmental Science, Manonmaniam Sundaranar University, Alwarkurichi, providing the support for this research work.

\section{REFERENCES}

Anandalakshmi, K; Venugobal, J; Ramasamy V (2006). Characterization of silver nanoparticles by green synthesis method using Pedalium murex leaf extract and their antibacterial activity. Appl Nanosc. 6:399-408

Anupam Roy, O; Sudip, S; Amit, K; Deniz Yilma, M (2019). Green synthesis of silver nanoparticles: biomolecule-nanoparticle organizations targeting antimicrobial activity. $R S C A d v$, 9:2673-2676.

Arvizo, RR; Bhattacharyya, S; Kudgus, RA; Giri, K; Bhattacharya, R; Mukherjee, P(2012) Intrinsic therapeutic applications of noble metal nanoparticles: past, present and future. Chem. Soc. Rev, 41.2943-2970.2012

Ashok, K; Sivakumari, KS; Rajesh D (2018). Achyranthes Aspera Mediated Green Synthesis of Silver Nanoparticles. Indo American Journal of Pharmaceutical Sciences, 5(1):64-73

Awwad, AM; Salem, NM; Abdeen, A (2013). Green Synthesis of Silver Nanoparticles Using Carob Leaf Extract and Its Antibacterial Activity. Int. J. Ind.Chem. 4:1-6

Balaji, DS; Basavaraja, S; Deshpande, R; Mahesh, D.B; Prabhakar, BK; Venkataraman, A (2009) Extracellular biosynthesis of functionalized silver nanoparticles by strains of Cladosporium cladosporioides fungus; Colloids and surfaces $B$ : Biointerfaces, 68(1):88-92

Bhattacharya, R; Mukherjee, P (2008). Biological Properties of "Naked Metal Nanoparticles. $A d v$. Drug. Deliv. Rev, 60.1289

Chandran, S.P; Chaudhary, M; Pasricha, R; Ahmad, A; Sastry M (2006). Synthesis of gold nanotriangles and silver nanoparticles using aloe vera plant extract. Biotech. Progress. 22 (2):577583

Cushing, BL; Kolesnichenko L; Connor CJO (2004). Recent advances in the liquid-phase syntheses of inorganic nanoparticles. Chemical Reviews. 104(9):3893-3946

Daniel, KSCG; Banu, NB; Harshiny, M; Nehrud, K; Ganesh, SP; Kumaran, S; Sivakumar, M (2012). Ipomea $\mathrm{M}$. carnea-based silver nanoparticle synthesis for antibacterial activity against selected human pathogens. J. Exp. Nanosci.1:1-13

Das, J; Paul Das, M; Velusamy P (2013). Sesbania grandiflora leaf extract mediated green synthesis of antibacterial silver nanoparticles against selected human pathogens. Spectrochimica Acta Part A: Molecular and Biomolecular Spectroscopy.104:265-270

Franci, G; FalangaGaldiero, A (2015). Disc plate method of microbiological antibiotic essay. Journal of Microbiology. 22(4):666-670

Franci, G; FalangaGaldiero, A (2015). Silver nanoparticles as potential antibacterial agents. Molecules. 20(5):8856-8874

Gan, L; Zhang, S; Zhang, Y; He, S; Tian, Y (2018). Biosynthesis, characterization and antimicrobial activity of silver nanoparticles by a halotolerant Bacillus endophyticus SCU-L. Prep. Biochem. Biotechno. A. 19:316-320

Giovanni, M; Pumera, M (2002). Size dependant electrochemical behavior of silver nanoparticles with sizes of $10,20,40,80$ and $107 \mathrm{~nm}$. Electroanalysis. 24:615-617

Henry, F; Aritonang, H; Okanagan, A; Audy D; Wuntu, D (2018). Synthesis of Silver Nanoparticles Using Aqueous Extract of Medicinal Plants. (Impatiens balsamina and Lantana camara) Fresh Leaves and Analysis of 
Antimicrobial Activity. International Journal of Microbiology. 8:1-8

Hoda Erjaee, H; Saeed, N (2017). Synthesis and characterization of novel silver nanoparticles using Chamaemelum nobile extract for antibacterial application. Vietnam Academy of Science \& Technology Advances in Natural Sciences: Nanoscience and Nanotechnology, 8(2): 85-88

Jirovetz, LG: Buchbauer, MP; Leela, NK (2003). Analysis of the essential oils of the leaves, stems, rhizomes and roots of the medicinal plant Alpinia galanga from southern India. Acta Pharmaceutica. 53(2).73-82

Li, S; Shen, Y; Xie, A (2007). Green synthesis of silver nanoparticles using Capsicum annuиm L. extract. Green Chemistry. 9(8):852 -856.

Mandal, S; Phadtare, S; Sastry, M (2005). Interfacing biology with nanoparticles. Current Applied Physics. 5(2):118-127

Marslin, G; Siram, K; Maqbool Q (2018) Secondary metabolitesin the green synthesis of metallic nanoparticles. Materials. 11(6):940-946

Milardovic, S; Ivaniševic. I; Rogina, I; Kassal1, P (2018). Synthesis and Electrochemical Characterization of AgNP Ink Suitable for Inkjet Printing. Int. J. Electrochem. Sci., 13: $1136-$ 11149

Oves, M; Aslam, M; Rauf, M; Qayyum, S; Qari, HA; Khan, MS; Alam, MZ; Tabrez, S;Pugazhendhi, A; Ismail, IM(2018). Antimicrobial and anticancer activities of silver nanoparticles synthesized from the root hair extract of Phoenix dactylifera. Mater. Sci. Eng. C 89:429-443

Qais, F; Samreen, A; Ahmad (2018). Broad-spectrum inhibitory effect of green synthesised silver nanoparticles from Withania somnifera (L.) on microbial growth, biofilm and respiration: a putative mechanistic approach. IET Nanobiotechnology. 12:325-335

Ratan, D; Siddarth, S; Natha, D; Gautam G; Ramendhu B (2014). Synthesis of silver nanoparticles and their optical properties. Journal of Experimental Nanoscienc. 8 (4):357-362.2014

Sathishkumar, M; Sneha, K; Won, S; Cho, CW; Kim, S; Yun, YS (2009). Cinnamon zeylanicum bark extract and powder mediated green synthesis of nano-crystalline silver particles andits bactericidal activity. Colloids Surf. B73:332-338

Sasidharan, D; Namitha, TR; Johnson, SP; Jose, V; and Mathew, P (2020). Synthesis of silver and copper oxide nanoparticles using Myristica fragrans fruit extract: Antimicrobial and catalytic applications. Sustain. Chem. Pharm. 16: 100255

Shanmuganathan, R; MubarakAli, D; Prabakar, D; Muthukumar, H; Thajuddin, N; Kumar, SS; Pugazhendhi, A (2018). An enhancement of antimicrobial efficacy of biogenic and ceftriaxone-conjugated silver nanoparticles: green approach. Environ. Sci. Pollut. Res.25:10362-10370

Singhal, G; Bhavesh, R; Kasariya, K; Sharma, AR; Singh, RP (2011). Biosynthesis of silver nanoparticles using Ocimum sanctum (Tulsi) leaf extract and screening its antimicrobial activity. Journal of Nanoparticle Research. 13 (7):29812988

Skandalis, N; Dimopoulou, A; Georgopoulou A (2017). The effect of silver nanoparticles size, produced using plant extract from Arbutus unedo. on their antibacterial efficacy. Nanomaterials. 7(7):178-182

Solomon, SDM; Bahadory, AV; Jeyarajasingam, S; Rutkowsky, A; Boritz C (2007) Synthesis and study of silver nanoparticles. Journal of Chemical Education. 84(2):322-325

Welch, CM; Compton, RG (2006). The use of nanoparticles in electroanalysis: a review. Anal. Bioanal. Chem, 38:601-619

Yang, Y; Jin, P; Zhang, X; Ravichandran, N; Ying, H; $\mathrm{Yu}, \mathrm{C}$; Ying, H; Xu, Y; Yin, J; Wang, K (2017). New epigallocatechin gallate (EGCG) nanocomplexes co-assembled with 3-mercapto1-hexanol and $\beta$-lactoglobulin for improvement of antitumor activity. Biomed. Nanotechno. 13:805-81

Yoon, WJ; Jung, KY; Liu, J; Duraisamy, T; Revur, R; Teixeira, FL; Sengupta, S; Berger, PR (2010). Plasmon-enhanced optical absorption and photocurrent in organic bulk heterojunction photovoltaic devices using self-assembled layer of silver nanoparticles. Sol. Energy Mater. Sol. Cell. 94: 128-132. 